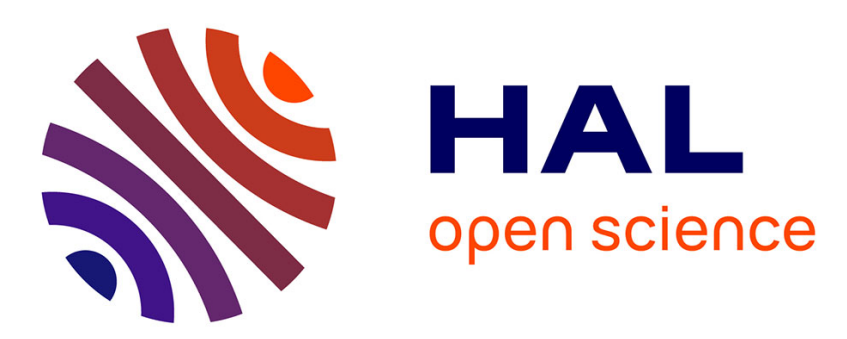

\title{
Banning Caesareans or Selling 'Choice'? The Paradoxical Regulation of Caesarean Section Epidemics and the Maternal Body in Turkey
}

\author{
Sezin Topçu
}

\section{- To cite this version:}

Sezin Topçu. Banning Caesareans or Selling 'Choice'? The Paradoxical Regulation of Caesarean Section Epidemics and the Maternal Body in Turkey. Politics of the Female Body in Contemporary Turkey: Reproduction, Maternity, Sexuality, 2021. hal-03514679

\author{
HAL Id: hal-03514679 \\ https://hal.science/hal-03514679
}

Submitted on 6 Jan 2022

HAL is a multi-disciplinary open access archive for the deposit and dissemination of scientific research documents, whether they are published or not. The documents may come from teaching and research institutions in France or abroad, or from public or private research centers.
L'archive ouverte pluridisciplinaire HAL, est destinée au dépôt et à la diffusion de documents scientifiques de niveau recherche, publiés ou non, émanant des établissements d'enseignement et de recherche français ou étrangers, des laboratoires publics ou privés. 


\title{
Banning Caesareans or Selling 'Choice'? The Paradoxical Regulation of Caesarean Section Epidemics and the Maternal Body in Turkey
}

\author{
Sezin Topçu
}

\section{Introduction}

With the highest acceleration rate among member countries, Turkey is the OECD champion when it comes to caesarean sections (CSs). In 2012, the Anglosphere press reported it as the first country in the world to ban elective C-sections in order to stop the national CS epidemic'. The expression 'caesarean epidemic' refers to contexts in which the use of CSs has become too high to be medically justified. The number of countries around the world affected by the normalization of CSs (Brazil, USA, China, Mexico, etc.) is increasing to such an extent that international organizations such as the World Health Organisation and the International Federation of Gynecology and Obstetrics have intensified their calls for a halt on the globalization of the problem (World Health Organisation, 2015; Visser et al., 2018). The many reasons for CS normalization have been tackled in depth in the social sciences literature (Diniz \& Chacham, 2014; Mc Callum, 2005; Roberts, 2012; Morris, 2013; Wolf, 2018). However, this is only the tip of a very modern iceberg. This CS epidemic is just one manifestation of a systemic problem, namely the overmedicalization of the maternal body and the 'fordization' of the childbirth process through the routinization of medical interventions whose benefits and (iatrogenic) risks are not always evaluated, studied or recognized objectively (Topçu \& Brown 2019; Sarda, 2011; Maffi, 2015). The arguments put forward for this overmedicalization are birth safety and the standardization and rationalization of maternal care. However, ecofeminists, natural birth activists and critical birth ethnographers have argued that it can also be seen as the by-product of a patriarchal society in which women and their bodies are controlled by medical experts in the name of science, modernity, capitalist profit or pronatalist conservatism (Gaskin, 2008; Davis-Floyd \& Sargent,1997; Jordan, 1978; Kitzinger, 2015; Odent, 1992).

Most countries with a 'CS epidemic' have been quick to implement state measures to regulate the problem, but these have not always been effective (Mc Callum, 2005; Diniz et al. 2018; Wolf, 2018). Their policy-makers have sometimes been forced to admit that the problem is beyond their control or more simply that the rates do not reduce despite the measures undertaken. Turkey is one of these countries. In 2012, its Justice and Development Party (JDP) government introduced what was presented in the media as a 'Csection ban'. This was preceded by an unexpected and provocative polemic from the then prime minister, Recep Tayyip Erdogan, who, in May 2012, claimed that 'Both caesarean

\footnotetext{
${ }^{1}$ See, for example, 'Turkish doctors face fines for elective caesareans', The Guardian, 13 July 2012 https://www.theguardian.com/world/2012/jul/13/turkish-doctors-fines-elective-caesareans
} 
births and abortions are murder'2. At a time when the government was accelerating its pronatalist offensive, Erdogan said CS delivery was not only a hidden family planning tool that prevented women having more than three children (in Turkey, the medical norm of 'once a caesarean always a caesarean' is valid, and quite often a tubal ligation is carried out during the third birth procedure because medical organizations consider more than three CSs to be risky) but also a conspiracy tool against the Nation and the rise of a 'strong', 'young', 'populated' Turkey. In response to Erdogan's criticisms, the government promptly modified the existing law which dated back to 1957, stipulating that 'C-sections should be carried out for medical reasons only', and Turkey's Ministry of Health declared that doctors who abused CSs would be sanctioned. This legal modification (2012) was called the 'caesarean law' by the media. The Ministry of Health also added, however, that a woman's anxiety about giving birth was considered a medical reason and therefore justified a CS. In economic terms, the sanction was quickly made concrete through the government's decision to reduce the level of its approved public health insurance cover for CSs, and through the reduction of performance points attributed to CS births (CS was lowered to the category of basic operations, like appendicitis). An organizational benchmarking process was also implemented in 2012, whereby the monthly CS data from each maternity hospital were reported to the Ministry of Health. When the CS polemic emerged (2012), the national CS rate was 48\%. Despite the 'ban' and the regulatory measures put in place, however, the CS rates continued to rise, from $48 \%$ in 2012 to $50.4 \%$ in 2013, 51.1\% in 2014 and 53.1\% in 2015, 2016 and 2017 (The Ministry of Health of Turkey, 2018: 80).

In 2016, the debate around why the rates had continued to increase despite the new law was opened up to the public in the national press. Among the many reasons put forward, medico-legal issues were considered the biggest factor by the public authorities and professionnal organizations. The latter complained that obstetrician-gyneacologists (OGs) did not have sufficient protection against legal action in cases of a medical accident. Other contributing factors included the woman's 'preference' for a CS or their anxiety about a vaginal birth, the absence of alternatives for managing birth pain such as epidural anaesthesia and the inadequacy of midwifery training. In February 2017, the public was informed that scientific commissions would be set up by the government to monitor hospitals with the highest CS rates and to train medical teams that 'do not know' how to supervise vaginal births ${ }^{3}$. Positive encouragement mechanisms were also envisaged for doctors with low CS rates. In January 2017, a ministerial commission published the names of approximately 150 OGs practising in (both public and private) hospitals in Istanbul who had 'appreciably low' CS rates, especially for primary births, and who were to receive awards (Ministry of Health of Turkey, 2017: 116-128). At the end of 2017, the Ministry of Health announced that a new CS law was being drafted that would, in particular, protect $\mathrm{OGs}^{4}$.

\footnotetext{
2 See, for example : 'Basbakan: Sezaryen cinayettir' (PM: Caesarean delivery is a murder), Kanal Türk, 27.05.2012 http://beyazgazete.com/video/anahaber/kanalturk-32/2012/05/27/basbakansezaryen-cinayettir-283466.html. Unless otherwise indicated, this and all subsequent quotations from Turkish sources have been translated into English.

3 'Cok sezaryen yapan hastaneler degerlendirmeye alinacak' (hospitals with high caesarean rates will be put under surveillance), CNN Türk, 10.02.2017

https://www.cnnturk.com/video/saglik/sezaryen-ile-dogumu-azaltmak-icin-yeni-yasa-geliyor 4 'Sezaryanla dogumu azaltmak icin yeni yasa geliyor' (a new law is being introduced to decrease caesarean rates), CNN Türk, 15.12.2017 https://www.cnnturk.com/video/saglik/sezaryen-iledogumu-azaltmak-icin-yeni-yasa-geliyor
} 


\section{Methodology}

In this chapter, I would like to propose an ethnographic contribution to this debate. I designed my research with the aim of understanding the impact of the 'ban' and its associated regulations on obstetric practice in public and private maternity hospitals from a comparative perspective. The first stage of my research (2014-2015) consisted of longterm observations in two hospitals - one public (Public Hospital \#1), one private (Private Hospital \#1) - in an average-size city in Turkey's Marmara region (population = 140K). I observed a total of 20 deliveries (both vaginal and CS in both hospitals) and conducted extensive interviews with OGs, midwives and mothers. During the research period, the maternity service team at Public Hospital \#1 comprised 3 OGs and 6 midwives, and its annual birth rate was approximately 1,200. The maternity service team at Private Hospital \#1 was much smaller, with 2 OGs, 2 midwives and 1 nurse, and its annual birth rate was approximately 500. Private Hospital \# 1 is a 'standard' one with an agreement with the social health insurance system (Sosyal Güvenlik Kurumu-SGK), which implies that public insured patients can receive medical care there with some extra payment. In case of a convention with the SGK, which became widespread with the recent health reforms, the rate of extra payment to be charged to publicly insured patients should be declared and, in theory, they can't exceed $200 \%$. This was the rate declared by Private Hospital \#1.

The second stage of my research (2015-2016) consisted of following the work of 6 OGs who, in addition to their obstetric practice, were engaged in the evaluation and regulation of CS norms and practices. Two of them were members of the TJOD (the Turkish Society of Gynecology And Obstetrics), two were a member of the TTB (the Turkish Medical Association), and two were regular members of scientific or advisory bodies set up by the Ministry of Health on issues relating to CSs and childbirth. These OGs worked in 4 different settings in Istanbul: a long-established private practice (the $O G$ in charge of the practice also worked in some prestigious public and private hospitals); a newly established private practice that promoted alternative birthing methods (the OG who had founded it also practised in a few luxury private hospitals where he rented birthing rooms for his clients); a large public university hospital (Public Hospital \#2) that specializes in gynecology, obstetrics and paediatrics and deals with a large number of high-risk pregnancies; and a luxury private hospital (Private Hospital \#2). The maternity service team at Public (University) Hospital \#2 comprised 10 OGs, 10 intern doctors and 30 midwives and nurses. Its birth rate in 2016 was approximately 7,600. The maternity service team at Private Hospital \#2 in 2016 comprised 7 OGs, 1 intern doctor and 4 midwives (who worked as both nurses and birth assistants). Its birth record in 2016 was 1,050 (See Table 1). In addition to the in-depth interviews I recorded with these OGs, who all had a high public profile, I carried out interviews with those who worked alongside them (midwives, nurses, students). Finally, I observed the antenatal courses offered by Public Hospital \#2 in Istanbul. Because such courses were rare in Turkey until only recently, many women attended these courses even though they were not necessarily going to give birth at that university hospital. The midwives who led these courses had never supervised a birth themselves but were perfectly qualified to train and support women and couples in 
preparation for vaginal, non-intervention and even orgasmic births 5 .

Table 1: Brief presentation of hospitals that were subject to the study*

\begin{tabular}{|c|c|c|c|c|}
\hline & $\begin{array}{l}\text { Public } \\
\text { Hospital \#1 } \\
\end{array}$ & $\begin{array}{l}\text { Private } \\
\text { Hospital \#1 } \\
\end{array}$ & $\begin{array}{l}\text { Public Hospital } \\
\# 2\end{array}$ & $\begin{array}{l}\text { Private Hospital } \\
\# 2\end{array}$ \\
\hline Location & $\begin{array}{l}\text { Marmara } \\
\text { region }\end{array}$ & $\begin{array}{l}\text { Marmara } \\
\text { region }\end{array}$ & $\begin{array}{l}\text { Istanbul } \\
\text { (Anatolian rive) }\end{array}$ & $\begin{array}{l}\text { Istanbul } \\
\text { (European rive) }\end{array}$ \\
\hline $\begin{array}{l}\text { Number of } \\
\text { births per year }\end{array}$ & 1200 & 500 & 7600 & \\
\hline $\begin{array}{l}\text { Volume of } \\
\text { medical } \\
\text { personnel }\end{array}$ & $\begin{array}{l}3 \text { OGS, } 6 \\
\text { midwives, } 3 \\
\text { intern } \\
\text { midwives }\end{array}$ & $\begin{array}{l}2 \text { OGs, } 3 \\
\text { midwives/ } \\
\text { nurse }\end{array}$ & $\begin{array}{l}10 \text { OGs, } 10 \text { intern } \\
\text { doctors, } 30 \\
\text { midwives/nurses }\end{array}$ & $\begin{array}{l}7 \text { OGs, } 1 \text { intern } \\
\text { doctor, } 4 \\
\text { midwives/nurses }\end{array}$ \\
\hline $\begin{array}{l}\text { Convention } \\
\text { with SGK? }\end{array}$ & Public & Yes & Public & Yes \\
\hline $\begin{array}{l}\text { Rate of extra } \\
\text { payment to be } \\
\text { charged to } \\
\text { publicly } \\
\text { insured } \\
\text { patients }\end{array}$ & - & $200 \%$ & - & unknown \\
\hline
\end{tabular}

*These data were collected during field research. They correspond to the period 20142015 for the Public Hospital\#1 and Private Hospital\#1 ; the period 2015-2016 as to what concerns Public Hospital\#2 and Private Hospital\#2.

I have already described elsewhere the technocratic nature of obstetric care provided in the public and private hospitals where I conducted my research. I have highlighted, in particular, the absence of alternatives to overmedicalization in these hospitals for both CS and vaginal deliveries (Topçu, 2019). During my field research, in the name of safety, vaginal births were organized and managed in a highly medicalized way (enema and ocytocin induction were widespread, women were continuously attached to monitoring devices, episiotomies were performed very frequently, etc.). Such an "agressive management" of vaginal birth (Diniz et al. 2018), with interchangeable cuts either "above" or "below" (Diniz \& Chacham, 2004), constituted an obstacle to the woman's autonomy during childbirth. I have argued that it also helped to promote CS as a better alternative to vaginal birth. Indeed, vaginal birth is commonly called "normal birth" in Turkish, but in the last decades, it has been mostly managed as an abnormal and high-risk event requiring many medical interventions (Cindoglu \& Sayan-Cengiz, 2010). I have also underlined the fact that CS delivery became a medical 'culture' among many OGs and even midwives. This 'culture' developed as a consequence of many factors: the health professionals' lack of confidence in women's capacity to give birth in an autonomous way; a combination of loss of skills and even professional role among midwives and OG training that was focused more on producing surgeons than accoucheurs; the positive professional and social

\footnotetext{
${ }^{5}$ Fieldnotes, 16 February 2015, Public Hospital \#2, Birth training room, Istanbul.
} 
representations of the CS as a modern, safe, painless birthing method (most of the midwives' and OGs' children had been born by CS); and the advantages that CSs offered practitioners in terms of saving time (it is a faster procedure) and/or organizing hospital space (especially in the private hospitals). My field research also revealed the importance of medico-legal risks in orienting the OGs towards CS delivery, although this risk appeared to be mostly indirect or hypothetical as far as their personal experience was concerned. Of the 15 OGs I interviewed, only one told me that he had been faced legal action because of a birth procedure accident. When asked 'Have you ever faced legal action because of a vaginal birth complication?', the others responded that they had not but that some of their colleagues had. Some mentioned the recent, highly publicized cerebral palsy case, which resulted in a record compensation payout (of 2.5 million YTL) following a ruling that the OG in question had opted for a CS too late despite alarming signs of foetal distress (Arman, 2015). This case helped the participants explain why OGs were often reluctant to go down the 'risky route' of vaginal birth. Some criticized the fact that a birth complication had never been defined in Turkey and that the boundaries between a medical error and a medical complication had never been made clear. They also blamed the 'CS law', which they saw as just a tool to transform Turkey into a 'little America' without the necessary insurance infrastructure in place for OGs. Some also pointed the finger at the 2004 Turkish Criminal Code law (TCK 2004) ${ }^{6}$ claiming that it had led to a normalization of legal action against OGs and that the OG community had therefore developed a self-defence reflex by systematizing CSs.

In this chapter, I propose to go beyond an explanation of the causes of CS epidemics. The totality of the above-mentioned cultural, political, juridical, professional and gendered elements have contributed and continue to contribute to its expansion. I propose rather to tackle one simple question. What impact did the 'caesarean law' have in the public and the private sectors? To answer this question, I will explore two closely related questions. To what extent have the recent regulations on CS epidemics contributed or not contributed to bringing it under control? And what do all these changes tell us about the new economy and politics of the maternal body in contemporary Turkey?

\section{Turkey's Health Transformation Program, the public/private sector dichotomy and the CS controversy}

The CS delivery rate in Turkey almost quadrupled in the space of nearly two decades (13.9\% in 1998, $21.2 \%$ in $2003,36.7 \%$ in $2008,53.1 \%$ in 2016). The rapid rise in CS rates during the 2000s was closely related to a contemporaneous boom in the private hospital sector, which recorded the higher CS birth rate $(70.5 \%$ in 2016). While the public hospital sector saw only a relatively modest growth (from 774 to 879) between 2002 and 2017, the number of private hospitals more than doubled (from 271 to 571) (Ministry of Health of Turkey 2018: 113). The public procurement of health care services from the private sector, the resurgence in public health care expenditures, the indulgent provisions for extra billing by private health care providers and the investment subsidies allowed such important growth in the private hospital sector and bolstered both global funds investments and

\footnotetext{
${ }^{6}$ According to the 2004 Turkish Criminal Code law (n5237) (26.09.2004), known as TCK 2004, provoking injury or pain in a person's body (including a pregnant woman) engenders a prison punishment of 3 to 12 months, or a financial fine (Article $n^{\circ} 89$ ).
} 
chain formation by some large hospital groups (Eren Vural, 2017: 276-277). Medical tourism also took off during these two decades, with its popularity increasing in parallel with the boom in luxury private hospitals being built in the big cities (Omay \& Cengiz 2013). On the overall, health expenditures expanded. While they corresponded to 5,5\% of GDP in 2000, the rate reached 6,7\% in 2011 (World Bank, 2018). Relevantly healthcare became a consumption good and patients' or clients' satisfaction became a priority concern for the JDP government(s). The highest acceleration rate of demands for medical care was recorded in the private sector. Between 2002 and 2017, while the annual volume of patient registrations in the public sector was multiplied by 3,2 (from nearly 110 million to nearly 354 million), it was multiplied by 12,7 in the private sector (from nearly 6 million to around 72 million) (Ministry of Health of Turkey 2018: 161). Out-of-pocket expenditures were multiplied by five (Turkish Medical Association, 2018a: 11). These changes came about as a result of Turkey's so-called Health Transformation Program (HTP) (2004-2012). HTP was launched thanks to program loans from the World Bank. It should be considered as one of the key pillars in the JDP's strong 'neoliberal turn' since 2002 (Acar \& Altinok, 2013).

The HTP introduced the so-called performance-for-pay (PFP) system and a number of benchmarking practices in hospitals alongside financial austerity measures for the public sector hospitals. As is the case for several national health systems in Europe, starting with France (Juven, 2016), each medical act was made accountable and attributed performance points. While, before the HTP, doctors were paid salaries, with the PFP, their remuneration took into account the number of patients they see and the medical acts they realize (Gok \& Altindag, 2015). In the public hospitals especially, the performance points collected by doctors at an individual level had an impact on the calculation of performance points for their department and even their hospital. In the private hospitals, these points were calculated on a more individual basis. The supplementary premiums or the profit shares for the OGs were negociated with the hospital's management on an annual basis. They were based on various medical interventions and their 'values' in the performance system. According to doctors' unions in Turkey, this point-based system resulted in a deterioration in working conditions for health professionals, both in public and private hospitals, due to increased workload and individual pressure (Turkish Medical Association, 2018b). Since 2011, physical and verbal violence against health professionnals also increased despite the augmentation of preventive measures (Hamzaoglu \& Türk, 2019). As a result, most of the OGs in my study were critical of the CS law and its associated regulations. They saw it as an authoritarian tool to further degrade their working conditions redefined by the HTP which was elaborated and implemented without the professional stakeholders' involvement (Wendt et al. 2013). They also believed that Turkey's conservative government aimed to use the law to gain greater control over both women and doctors. Considering the situation from a more macro perspective, some even claimed that the 'CS law' was part of the government's attacks on intellectuals in Turkey more generally. According to the OGs from the Turkish Society of Gynecology And Obstetrics that I interviewed, the 'CS law' had been passed without prior consultation with any professional organizations. This prompted them to file a legal challenge to the 'law' claiming it was a political invervention in their (scientific) practice. The OGs, like other specialist doctors, had already lost a number of privileges as a result of the HTP. For example, before the HTP was introduced, they could work part-time in a public hospital and part-time in their private practice. This structure was highly criticized by consumer groups because many doctors were suspected to recruit patients from the public hospitals in the mornings for a private, high-profit consultation in 
their practice in the afternoons. The HTP effectively forced doctors to choose between a job in the public sector and private practice. In reality, however, most were only occasionally able to combine the two because the JDP government overtaxed private practice as a dissuasive measure. Professionnal organizations, such as the Turkish Medical Association, criticized the new regulation for being a political strategy aimed at transferring doctors to the newly established private hospitals at a lower cost (Turkish Medical Association, 2011). In other words, if their option to combine private practice and hospital work had not been constrained, it would have been difficult to convince them to work in private hospitals without offering very high salaries. The OGs who adhered to the government's political line more closely, however, such as the head of the maternity service at Public Hospital \#2 in 2015-2016, had a different appreciation of the HPT:

'There's also a false perception among doctors. They think that the (JDP) government's always working against us. This is a very common perception. Turkish doctors think "I'm a specialist now so I should have my own office, and I should earn 50K, $100 \mathrm{~K}$ per month". Until the 2000s, they all thought like this, didn't they? Most of them still do. Does anybody earn that much in Europe? No. When I go to Spain, I meet fellow doctors who say "We barely earn 5,000 euros a month. I go to Portugal to do some extra surgeries at the weekends". When I go to Germany, my colleagues there say "If you're a specialist doctor, you earn 4,000 euros here. If you're head of the clinic, you earn 6,000 or 7,000 euros, but then you mostly use the salary difference mainly for professionnal purposes" (...) What was the system like before in Turkey? I used to work as a state doctor in the eastern cities. Before, being a state doctor meant you went wherever the state wanted you to go. And then you worked for yourself (in your private practice) from morning to evening. It was enough just to do two surgeries a day in the public hospital, where you were employed, and then you would go back to your practice. I'm not going to lie, we used to earn 20 or even 30 thousand dollars a month doing this. As a specialist doctor. But the system couldn't go on like this. It was impossible'.

Regardless of the OGs different reactions to the HPT, very few media commentators or public experts had linked up the boom in CS rates with the rapid rise in the number of private hospitals since the HTP was launched. The then prime minister Erdogan's condemnation of CS delivery (describing it as murder) meant that the 'CS law' was seen more as an authoritarian, pronatalist, conservative tool than an intervention aimed at repairing the side effects of the government's neoliberal health project. As already mentioned, the expansion of private hospitals was one of the HTP's key objectives, but the 'abuse' of CSs engendered by the project now seemed to need to be brought under control. The JDP government officials in particular stressed the need to increase national fertility rates through the CS regulations in order to build a young, populated, 'big' Turkey that would be the strongest new force in the region. Another significant albeit discreet motivation for the 'CS law' was that it would lead to savings in public health expenditure (Ministry of Health of Turkey, 2017), which had grown by 7.7\% over the last decade (compare to $1.9 \%$ in Germany for instance in the same period) (Wendt et al. 2013: 93). The calculations were clear: birth costs almost doubled in case of a CS (Özer et al. 2016: 264). One of the OG's from TTB criticized this issue in the following way:

'They [the government officials] introduced the staff called the HTP, in order to seduce people and gain new electors. Then they realized that the national budget is not sufficient to implement it. They started to ask themselves 'How can I cut costs?' They realized that C- 
sections cost too much, that the cost of anaesthesia, operation room etc. are too much. They said to the PM: 'We should do economies on C-sections'. The PM replied: 'All right, I will deal with that'. And the next day he came in front of the cameras to say that C-section is a murder!'

\section{Public hospitals: towards a new economy and politics of the maternal body}

\section{Supporting OGs, banning elective CSs}

In Public Hospital \#1, all the OGs I interviewed told me that they felt a high level of work pressure but that their salaries were satisfactory because of the performance points. Each had between 50 and 70 consultations in the polyclinic every afternoon, which meant that sessions lasted a maximum of approximately 2 minutes per expectant mother. In addition, once hospitalized for the birth, the women had no privacy because neither the labour wards nor the delivery rooms were closed off. There was also a high turnover of OGs in this public hospital. They frequently migrated to the private sector, particularly after the launch of the benchmarking system, which had added to their workload and stress, according to the interviewees. Moreover, hospitals now had to display the monthly CS rates for each OG by law, and these were presented on the wall behind the information desk at Public Hospital \#1's entrance. Sanctions or compulsary training courses provided by the Ministry of Health had also been put in place to discipline any doctors 'abusing' CSs. During my first observation phase, one of the OGs had already been 'sent' to Ankara for having the highest CS rates a number of times. Although most of the OGs I met said they did not pay any attention to the law, the regulatory practices did seem to have an impact because the CS rate in Public Hospital \#1 had fallen from $40 \%$ to $31 \%$ over 3 years. Moreover, in Public Hospital \#2, the head of the maternity service explained in 2015 that the lowering of CS rates through better support for OGs was a major aim for his service:

'C-sections became the modus operandi for OGs. And this still goes on. One of this year's quality goals in our hospital is to lower our C-section rates from $49 \%$ to $45 \%$. To achieve this, we're focusing on the psychology and feelings of our doctors by reassuring them that they will not be left stranded in the event of an accident. The TCK 2004 law [the 2004 Turkish Criminal Code law ${ }^{\circ}$ 5237] was a turning point for doctors in terms of medicolegal risks. It was adopted within the framework of a harmonization of our laws with those of the European Union. What I don't understand though is why these laws didn't cause any increase in CS rates in Europe, but at home they did. When I speak to doctors, they say "The TCK law is destroying us, it (a vaginal birth) can cost us 1 billion, 3 billion." Many legal actions were filed against the Ministry of Health. Some of them turned into lawsuits. But as far as public hospitals are concerned, very few accidents are judged to be a doctor's individual responsibility. Only around 3\%. See? In $97 \%$ of cases, the state takes responsibility for them. What does the state look at? It looks at whether the OG followed up their patient, whether their attitude resulted in an added complication or not. If the accident happens because of a medical complication, then the state takes responsibility for it. In this respect, there's a misunderstanding, an exaggeration of the medico-legal risks on the part of OGs.'

In addition to Public Hospital \#2's support for OGs and the dialogue it encouraged around the importance and safe nature of opting for vaginal birth, it also provided antenatal 
classes (6 sessions) for pregnant women (and couples). The midwives who led these classes did not, however, supervise any deliveries, which were the responsibility of either the doctors or intern doctors. In Public Hospital \#2, episiotomies in the case of a first birth were systematic, labour induction was frequent and birth on a gyneacological table was the rule. One of the midwives explained during our interview:

'We don't deal with deliveries because intern doctors should learn how to supervise them. But to be honest, if you want to, nobody would stop you. I have for instance already attended deliveries, I also practised episiotomy. But you should show you are willing to. Last year, the hospital management ordered a survey. Among the 30 midwives working here, only three said they wanted to attend births. The rest of them think that birth assistance is a hard job. They don't want to be involved in it (...) Most women who come to the training sessions do not give birth here. They are followed by a natural birth doctor, etc. Doctors and interns here wouldn't want women to be too informed or too demanding either. They would be afraid to cope up with them, and not to be able to do their businessas-usual.'

In Public Hospital \#1, which was much smaller than Public Hospital \#2, there was no antenatal classes provision at all during the research and writing-up period. Moreover, there were no major official incentives to make vaginal births more appealing to women. Some of the midwives took the initiative, purely on an individual basis, to attend alternative birth training courses, especially those provided by Dr Hakan Çoker, who founded the 'Birth With No Regret' academy in Istanbul. This academy is quite a lucrative, upper-class antenatal education centre, located in a comfortable, central quarter of Istanbul, but Dr Çoker had also been giving conferences and training courses on a more affordable and sometimes voluntary basis all around the country since 2012. One midwife at Public Hospital \#1 who had attended the courses in 2014 explained to me that she had been 'completely transformed' by this experience. However she was unable on her own to put her new knowledge (e.g. the fact that systematized episiotomy was not medically justified) into practice. The OGs and indeed most of the midwives at Public Hospital \#1 believed, for instance, that attaching a pregnant women to monitoring devices for most of her labour process was a medical necessity, that delivery on a gynecological table was the only legitimate birth position, that episiotomy was a must for safe first births (primipares) and that general anaesthesia was the best anaesthetic option in the case of a CS. It would take time and more importantly a change in mentality to replace these local 'truths' with others. It would also require a shift away from the quantitative regulation of the CS problem that the government proposed to a qualitative evaluation of the limitations of the dominant obstetric care system as a whole. Hence, the $8 \%$ reduction in CS rates in the short term in Public Hospital \#1 was related to factors other than a substantial change in birth practices. It seemed to be associated in particular with the fact that maternal demand for a CS delivery had been systematically refused since the 'law' had come into force. Before the 'law' was passed, it was easy for women who were anxious about a vaginal birth and who asked for a CS at their antenatal consultations to have their CS delivery scheduled.

\section{Giving birth in a public hospital: between obligation and choice}

The women who gave birth in Public Hospital \#1, where I conducted my ethnographic observations, had different motivations for choosing their place of delivery in the aftermath of the CS controversy. Most had chosen Public Hospital \#1 either because they did not have 
sufficient financial means or health insurance to give birth in even a modest private hospital or because of personal reasons, such as the fact that a close family member worked there. If this had not been the case, they told me, they would have opted for a private hospital. A sizeable percentage of the women who had chosen the public hospital for financial reasons continued to be anxious about vaginal birth and thus still hoped to have an OG who would be understanding about their vaginal birth fears and not too intractable on the vaginal birth issue. For example, when Gülcan (23 years old, $1^{\text {st }}$ pregnancy) arrived at the hospital at 2:30 am with contractions, she was immediately taken to the labour ward because there was no medical reason for her to have a CS birth. In the morning, she would repeatedly cry in the labour ward, loudly enough so that the midwives coud hear her. She told them a number of times that she could not bear the pain any longer and that she wanted a CS. At one point, she whispered to me 'They're not taking me to the operating theatre because I'm Kurdish not Turkish'. She did not realise that the same procedure applied to everybody. She also cried when she told me that nobody was bothered about her labour pain in the hospital. All the pregnant women were attached to monitoring devices most of the time. They were not encouraged to walk about, and they had not been given any breathing training. The midwives mostly spoke to them in a gentle and patient way but either chose not to or could not spare the time to accompany them during labour. They often said that the most important thing was to 'have a healthy baby in one's hands'. Indeed, they themselves had not necessarily been trained in labour-related processes, such as breathing exercices. When Gülcan's daughter was born by vaginal delivery a few hours later, she made fun of her insistence on a CS during her labour. She told me 'I'm happy now that they didn't do surgery on me. The labour pain was tough, but everything went well. I'm already up and feel good. The doctors didn't listen to me thankfully'.

By contrast, some women really did not want a CS birth and therefore came to the public hospital to increase their chances of having a vaginal birth even though this meant a less comfortable stay compared with the private hospital. For example, Didem (36 years old) felt lucky to have escaped a CS delivery when she gave birth to her first child in a university hospital in Ankara, although she would also have preferred not to have had an epidural anaesthesia: 'I had a negative experience with epidural anaesthesia. Your body loses all the strength it needs to push the baby out. I had this button in my hand that I had to press. The labour was just dragging on and on. In the end, the doctors came in and were annoyed with the interns and nurses because my baby had started to show signs of foetal distress apparently. They took the button out of my hand and speeded up the delivery. It was a big panic'. Didem was happy to be in a public hospital again for her second birth, especially because this was a more modest hospital where no epidural was offered at any point during my observations. She also chose Public Hospital \#1 because she felt that one of the OGs who worked there had provided more satisfactory responses to her questions during her pregnancy compared with the doctors in the private hospitals: 'When I asked Dr B in the private hospital when I was eight months pregnant what the approximate weight of my baby was, he said "I'm not a fortune-teller Madam". A scientist would be able to tell you!' She also told me she was uncomfortable with the commercial dimension of the private hospitals: 'There's also another aspect. There's uncertainty around the prices in the private hospitals. A friend of mine who gave birth in the private sector (Private Hospital \#1) couldn't get a bill when she left the hospital. Why not provide a bill? The prices apparently vary from one client to the next !" 
Aysel (36 years old, $1^{\text {st }}$ pregnancy) also came to the public hospital with a clear preference for a vaginal birth. She explained to me in the early stages of her contractions:

'Normal birth is better for your health. Even if they offered me a billion lira, I wouldn't want to be cut for no reason. I think it's important as well to feel the birth pain. I feel that because of the pain I will love my baby even more. (...) I was told that birth pain was a bit like a tooth abscess pain or a kidney pain. I've had both of them so I'm not scared of it'. Aysel's labour lasted 8 hours. In the middle of her labour, she started to cry desperately and begged for a CS several times, saying that she could not bear the pain any longer. She hit the delivery room walls so hard that one of the student midwives felt the need to check with the chief midwife whether the wall might cave in because Aysel was quite strong. Aysel finally had a vaginal birth. She felt uncomfortable and insecure as the intern midwife was stitching her episiotomy. She cried frequently during the repair, complaining at the pain again. The midwife who had injected the anaesthetic in three places' in prepaeation reassured her that it was impossible for her to be able to feel the pain and that what she could feel was just a little scratch from the needle's point.

Finally, some women came to the public hospital with no clear preference for a CS or a vaginal birth. They were simply happy to follow what the doctor prescribed. However, some (like Didem) had also made contact with a private hospital so that they had an alternative option just in case they were 'forced' to have a vaginal birth or they were 'mistreated'. Indeed, during my two-month research stay at the public hospital, these kinds of situations occurred on a few occasions, prompting the women to go instead to a private hospital.

Azize (31 years old, $1^{\text {st }}$ birth) arrived at the hospital on the morning of her baby's due date, even though her contractions had not yet started. She registered and explained to the midwives at the information desk that her most recent ultrasound scan had shown her baby was breech and that the OG who had examined her had told her she would have to have a CS delivery if the baby had not changed its position by the due date. Azize was given another ultrasound scan, which confirmed that the baby was still breech. However, the OG on call that day was not the same OG who had examined her previously, and he was the only doctor in that maternity service who liked to 'try' vaginal births first in the case of breech babies. He thus told the midwives that Azize should be taken to the labour ward. Azize objected, explaining that she should have a CS. The on-call OG replied 'I'm the doctor here, not you, so I decide which treatment to prescribe to my patients. If you don't want to try vaginal birth, you can leave'. Azize reflected for a few minutes and then retrieved her documents and left for one of the two private hospitals in the town. The midwives on duty strongly criticized the OG on this matter. They believed that he generally took unnecessary risks and that he expected women to do the same. They said Azize had the right to have a CS in this case.

The case of Nevra (33 years old) was different because she had already had 2 CSs. Her $3^{\text {rd }}$ birth was therefore necessarily an elective CS delivery, and her doctor was insisting she had a tubal ligation. I was not allowed to attend these consultations personally, but the case was reported to me by the doctor in question. While I was interviewing him in his office, a midwife knocked on the door. She said 'The patient with the planned C-section has accepted'. The doctor nodded his head, pleased at her response. He told me: 
'Here's another sociological case for you. There's a pregnant woman who's going to have her third child. She had a C-section with the first two. Now she's going to have a C-section again. I'm the one who operated on her the first two times, and I'm due to operate on her again this afternoon. I told her, during the consultation today, that she'd also have to have a tubal ligation. She didn't want one. So I told her, if that was the case, I wouldn't be able to do her surgical delivery, that she'd have to find another doctor. Apparently she thought about it for a bit. She's accepted now, after some gentle persuasion (...) I can't bear any responsibility in such cases because, beyond the third, a caesarean operation is too risky'.

Unlike Azize, Nevra did not have the means to go to a private hospital where, according to the private-hospital OGs I interviewed, she would have been free to refuse tubal ligation. In other words, the more the public hospitals implemented authoritarian practices and restrictions (including restricted abortion service) the more the private hospitals were reframed as places where the woman's choice would be respected and abided by (provided she could afford it). In this respect, the 'CS ban' contributed to reinforce this positive image of the private sector. More importantly, it led to the privatization of a state service (i.e. elective CSs), just like abortion services were silently privatized (O’Neil, 2017).

\section{Private hospitals: towards the privatization of women's 'choice'}

\section{From CS ban to commercial birth}

In contrast to the public hospitals, there was no drop in the CS rates after 2012 for the two private hospitals studied. In Private Hospital \#1 for instance, the rate increased from 79\% in 2012 to $83 \%$ in 2013 and then to $85 \%$ in 2014. Despite these very high CS rates (which the hospital justified by the prevalence of repetitive CSs), none of the OGs was sanctioned during the field research period, unlike in Public Hospital \#1. The OGs and the hospital management at Private Hospital \#1 both complained to me about the amount of government surveillance they were subject to. However, their complaints seemed more related to the new measures the government had put into place to prevent fraud associated with health insurance reimbursements. There had been many cases reported nationally over recent years of patients receiving treatment in private hospitals under other people's insurance policies because they themselves were not insured. To prevent this, the government had (at the time of the research) introduced a compulsory 'biometric finger and palm print' hospital registration system. This was a controversial measure denounciated by the TTB as a violation of privacy of personal information laws (Turkish Medical Association, 2013). It was also considered by private health service providers, such as the Private Hospital \#1's management, to be an insult to them. The CS 'ban' and its associated regulations seemed to concern them less. The chief executive of Private Hospital \#1 recalled during our first interview that CS deliveries were 'banned' but then immediately added: 'As a result, women are knocking on the doors of private hospitals more'. Clearly, in his view, the 'ban' primarily concerned public hospitals. A similar perception also seemed to be prevalent in Private Hospital \#2. One of the OGs there told me during our interview (in 2015):

'I don't know whether the sanctions for C-section abuse are still valid, or if they ever happened in this hospital. I was only appointed chief of the maternity service three months 
ago, so I don't know. I haven't seen a sanction case yet. But it can happen. The government wants to sanction OGs.'

This same OG explained that the high CS rates in his hospital, which he confirmed were approximately ' 70 or $80 \%$, something like that'7, were not likely to reduce because of women's preferences for CS:

ST: Why are the C-section rates much higher in the private sector than the public sector?

OG: Women's demand for C-sections is one major reason.

ST: Why do women in Turkey want to have a C-section in your opinion? Is it because of a lack of pain management, such as access to epidural anaesthesia?

OG: Yes, pain's an important factor. There is a lot of suffering in our society. People don't want to experience pain in childbirth or at any other time. Fear's also an important factor. There's a lack of education. Sex education for instance is very poor in our country. So women are afraid.

ST: Most women who come to your hospital have quite a specific socioeconomic status. Even they're lacking in knowledge? And I guess some of them would prefer a 'normal birth' to a caesarean birth?

OG: Yes, some of them come and say that they want a normal birth. But that's not really because they want it. It's because it's become fashionable to have a normal birth. Because the media promotes it. Water births have become quite trandy. Or some want to give birth crouching or standing. There are some alternative staff ("süslü püslü isler ») out there that's became quite fashionable, a trend. Women don't ask for all these because they know what they want. The main problem is the preparation for the birth. There are no proper training courses for mums and dads beforehand. So when women who want to have a normal birth go into labour and start to feel the pains, they immediately ask for a Csection.'

Although this OG cited the lack of antenatal classes for pregnant women as being one of the key determining factors, even his own prestigious and expensive hospital did not offer any training sessions to help women manage a vaginal birth. In 2017, it started to offer one-day birth seminars to women, but it does not include either physical exercises or group discussion sessions. It comprises only theoretical talks given by OGs, midwives and anaesthetists on, for instance, birth complications, breastfeeding and common infant illnesses.

It should be mentioned here that, over recent years, the private hospitals introduced 'birth packages' to make the prices more attractive. Surprisingly, antenatal classes are almost never mentioned in these packages, demonstrating they are not a priority either for the hospitals or for the women who choose to give birth in them. For instance, according to Private Hospital \#2's call centre agents in early 2020, its 'birth package' included the following services as standard:

Call Centre (Private Hospital \#2): I am just looking that up on the system for you. The system is just loading, thank you for your patience. So, the caesarean birth package includes: the rental of the operating theatre for the mother, the blood tests, 2 night's

\footnotetext{
${ }^{7}$ It was not possible for me to access more accurate data on the CS rates for Private Hospital \#2, where I did not conduct ethnographic observations, only interviews.
} 
private room service for the mother and baby, 2 night's hosting of the birth partner with 3 meals a day, one breastfeeding training session provided by the nurse, nutritional diet advice for the mother, Turkish delights and sherbet offered to the visitors, a special celebration dinner for the new baby's parents, hairdressing service for the mother. For the baby, the package includes the routine blood tests, scans, a paediatric consultation after birth, an ophtalmologic examination, a hearing test, the first dose of the hepatitus B vaccination, all examinations and checks carried out during hospitalization, one follow-up visit at home by the medical team, a newborn baby pack containing baby plasters, shampoo, baby oil, lotion, photos of your baby and their publication on our 'e-bebek' website, a lifelong price promotion for the baby on his/her medical consultations at our hospital, with a $20 \%$ reduction on consultation prices during childhood, $10 \%$ reduction after the age of 18.

ST: Interesting. What is the content of the birth package in the case of a normal (vaginal) birth please?

CC : The same thing, if it is a single pregnancy. The only difference is that there is one night's hospitality for the patient and her birth partner instead of two.

ST: Are antenatal classes included in these birth packages?

CC: I'm just checking in the system, thank you for waiting ... hmm, only the breastfeeding training and nutritional diet advice are included.

These birth packages, which did not include any birth preparation courses (unlike those offered by some European maternity hospitals, like breathing classes, group discussions, yoga, sophrology, acupuncture, haptonomy, etc.), cost 9,500 YTL if the woman had public health insurance (SGK) and if she wanted her birth to be supervised by a top obstetrician (a professor or associate professor). The prices were the same for both a CS and a 'normal birth'. They were slightly lower if the mother settled for just a specialist OG (8000 YTL) and slightly higher (10,000 YTL) if she had an epidural (vaginal) birth or a CS with an epidural or spinal anaesthesia instead of general anaesthesia. In cases where the woman had no health insurance cover, she had to pay an extra fee, which ranged between 5,800 and 7,400 YTL depending on the type of birth. These prices corresponded to the public insurance system's contributions to these packages. They were far beyond the contribution rates fixed for vaginal birth or CS alone (Özer et al. 2016). An OG from the TTB commented:

'Private hospitals offer hospitality services rather than health services, and they get good cover from the social health insurance system (SGK) for this. The more surgeries they perform, the more hospitalized patients they have. So they wouldn't want to reduce their Csection rates.'

Indeed, according to official statistics, while in $2002,76 \%$ of hospitalizations took place in the public hospitals, $14 \%$ in the university hospitals and $10 \%$ in the private hospitals, in 2017, the rates were as follows: 55\% public hospitals, 14\% university hospitals, 30\% private hospitals (Ministry of Health of Turkey, 2018: 166). The private hospitals thus clearly competed with public hospitals and took away from them a significant part of hospitalizations. Put differently, the number of hospitalizations augmented by $81 \%$ in the public hospitals, $627 \%$ in the private hospitals. And among the latter, by 2017 , the top 5 hospital chains made up for approximately $28 \%$ of the total private hospital market in terms of beds (Union of Chambers and Commodity Exchanges of Turkey, 2017). Furthermore, from 2002 to 2017, the annual volume of surgeries more than tripled countrywide. The ones realized in the public hospitals augmented by $160 \%$ (from over 1 
million to approximately 2,6 million), those in the university hospitals by $165 \%$ (from nearly $307 \mathrm{~K}$ to nearly $815 \mathrm{~K}$ ), while those taken in charge by private hospitals augmented by almost 584\% (from nearly $219 \mathrm{~K}$ to over 1,5 million) (Ministry of Health of Turkey, 2018: 166).

Coming back to birth training for women, Private Hospital \#1, where the prices were much lower (approximately a quarter of those in Private Hospital \#2) and the birth packages more modest, had not put on any courses at all since the CS 'ban' had been introduced. The most significant change in this hopital in recent years had been the promotion of vaginal births under epidural anaesthesia. The hospital had been advertising them as a 'painless birth' and even as a 'princess birth' since 2017. However, this had not led to a rapid uptake in epidural births, which would have reduced the hospital's CS birth rate.

\section{Choosing CS or dignity or both? Women's birth experiences in the private hospitals}

The women who chose private (over public) hospitals for their childbirth reported different motivations, but an epidural birth (which most public hospitals did not offer) was not one of the main reasons cited. Their main motivations were rather privacy (each patient had a comfortable individual room with ensuite shower and WC as well as a bed for their birth partner) and hygiene (some women reported rumours that 'rusty' episiotomy suturing needles were used in Public Hospital \#1!). Most women who chose the private sector also wanted their birth supervised by a doctor rather than a midwife (as was the case in Public Hospital \#1) and valued the personalized care on offer: they could choose their doctor from the outset and have both antenatal and delivery care provided by this doctor. Some women of low socioeconomic status had stretched their financial resources to have their birth in a private hospital for these reasons. As Selma (26 years old, $1^{\text {st }}$ pregnancy in 2014) explained: 'I started my antenatal care at the public hospital, but when I did my sums and took into account the minibus fares, etc., the private hospital is walking distance from my home but the public hospital isn't, it didn't really make a big difference. So why put up with the public hospital? (...) In the end, the bill was 1,500 YTL... or actually 2,000 YTL I think, if I count the trisomy 21 test when I was pregnant'. A homemaker with a high school diploma, Selma read a lot and was a passionate health and nutrition advocate. During her first pregnancy, she had told the OG in Private Hospital \#1 that she really wanted to have a 'normal' birth:

'During our monthly consultations, Dr F would listen to me carefully, but then she'd often say "You can try a normal birth but we can't tell at this stage how things will turn out on Dday, so you shouldn't set your heart on it'. I read a lot of things on the internet. I watched videos on how to do the breathing exercises, and I started to practise them at home everyday. Sometimes I did the exercises with my husband. One afternoon, exactly 2 weeks before my son's due date, I felt my first contractions. I told my husband I didn't want to go to the hospital straight away though. I was thinking that if my labour was well advanced, they wouldn't just automatically take me to the operating theatre. But within an hour, my contractions had become so strong that I started to get a bit anxious, and we went to the hospital. My hospital bag was ready anyway. When I arrived, my doctor was there. She examined me straight away and told me that the birth had started, that my cervix was half dilated! I told her that I was ready. I then felt things all went a bit strange. Kind of... she was stressed. Yes, she seemed very stressed. And she made me feel stressed! She was looking straight into my eyes. I did the same back. I felt she was trying to decide whether to take me 
to the operating theatre or not. Finally, 20 minutes later, the midwife reexamined me, and they took me to the delivery room. The OG told me to follow all her instructions. Everything was fine afterwards. My son came quickly. Overall, it was only about an hour, two max, between being admitted to hospital and my son being born. I think I gave birth so quickly as a defence mechanism. I wanted to do it before they could take me to theatre.'

A significant number of women I met in Private Hospital \#1 either before or after their deliveries told me that they, like Selma, wanted to have a 'normal birth' rather than a CS. Not all got their wish, however. In 2014, Leyla (25 years old), a high school teacher, felt strongly about having a vaginal birth and chose Private Hospital \#1 because her husband's aunt was one of the OGs there. Leyla placed a lot of trust in her and thought that she was her only chance of having a vaginal birth. Her pregnancy had proceeded without any complications. On her son's due date, the aunt proposed not to hospitalize Leyla but to monitor the foetus daily until her contractions started. On the $4^{\text {th }}$ day, however, Leyla said she became very stressed and was crying a lot. She was anxious about a vaginal birth. She had had no preparation for it. She was also impacted by her mother telling her that it was a pity she had decided to suffer instead of taking advantage of the CS opportunity. She suddenly felt powerless. She felt she would not be able to manage a vaginal birth. In the end, she and her husband's aunt made a joint decision to opt for a CS. Her aunt offered her an epidural rather than a general anaesthesia because she had initially wanted to actively participate in the birth of her child. However, after 3 attempts, the anaesthetist told the OG that they would need to use a general anaesthesia, adding 'She's put on a bit of weight. I'm afraid I can't get the needle in the right place in her back'. Leyla was upset about having to have a general anaesthesia. Her trauma was redoubled when she was woken up after the birth of her healthy baby. As she held her son in her arms for the first time, she saw on her smart phone that photos of her newborn baby had already been 'liked' by more than 300 Facebook friends. Her husband had sent the first photos of their son to one of their best friends, who had then posted them on Facebook. Several hundred people had seen Leyla's baby before she had.

Zeynep (28 years old, $1^{\text {st }}$ birth, $2^{\text {nd }}$ day after birth) also really wanted to have a 'normal' birth. In preparation, she had read a lot during pregnancy, learnt the breathing exercices, walked a lot and been careful not to put on more than 9 kilos. Her contractions had started at $6 \mathrm{am}$, and she arrived at the hospital at $9 \mathrm{am}$, just as her doctor was starting her shift. The OG examined her, told her she was '3.5-4 centimetres, which is good' and then asked the nurses to settle her into her own side room. At $2 \mathrm{pm}$, the $0 \mathrm{G}$ decided to accelerate the process by inducing Zeynep in order, they were all told, to 'give support to the birthing women'. Induction was a very frequent practice at this hospital. 'Apparently they did it because my baby was lazy,' Zeynep told me. She added 'Everything was going all right until they induced me, contractions, everything. But afterwards, the pain became unbearable. So Dr $\mathrm{N}$ asked me if I wanted an epidural anaesthesia. I didn't. I'm scared of it. In the end, at 4 pm, because my labour wasn't advancing as much as it should, Dr N came and told me "We don't want to tire you or your baby out anymore. Let's go for a C-section". So that's how things finished up. It wasn't a very happy ending. Now I get a lot of bloating in my belly'.

Aysen (25 years old, $1^{\text {st }}$ birth) was luckier in a sense. She had also wanted a vaginal birth from the outset, but during her first vaginal examination in the $3^{\text {rd }}$ month of her pregnancy, her doctor had told her that she was not 'relaxed enough' so she would probably not manage to have a normal birth. He added that it could be risky for the baby because she 
was stressed. Aysen came to the hospital at midnight, after her contractions had started. She had been asked to come in two days before that because she had already gone past her due date, but she had not done so because she did not want to be induced. By $4 \mathrm{am}$, her pain had become too much for her, and she asked the midwife to call the OG to come to the hospital and operate on her immediately. The OG refused. He arrived instead at 9 am for his shift, examined Aysen and told her that she was close to giving birth. The on-call midwife reminded him that the patient had asked for a CS several times during the night, but there seemed to be no need for one anymore. Aysen was taken to the delivery room in a wheelchair, and she gave birth to her daughter shortly after by vaginal delivery. She had changed her mind about having a CS several times during her labour, but in the end her labour had advanced so well that she had a vaginal birth.

Clearly, the OGs in Private Hospital \#1 did not refuse the women's requests for a 'normal birth' during pregnancy, but neither did they really encourage vaginal births, as the above cases show. Generally speaking, in Private Hospital \#1, all possible medical reasons for a CS, as defined by the government experts following the 'Robson classification' (Ministry of Health of Turkey, 2010), were mobilised. A 'previous C-section' was the main reason recorded, because VBAC (Vaginal Birth After Caesarean) was never practised in this hospital. The same was true of many private hospitals in Turkey, despite the fact VBAC is common practice in a large number of European countries since early 2000s. IVF babies, twin babies, breech babies and 'big' babies (i.e. babies who, according to the ultrasound, weighed $4 \mathrm{~kg}$ or more) were also all automatic reasons for a CS. For the women who wanted to give birth 'normally', provided that none of the above medical reasons applied, a number of non-medical factors were also taken into account by the OGs when deciding whether or not they would 'give normal birth a chance', as one midwife put it. One was the woman's determination to have a vaginal birth, as Selma's case showed. The duration of labour (and birth) was another important factor, as we saw in Zeynep's case. Because of concerns relating to time management, many women in Private Hospital \#1 ended up having CS deliveries after first 'trying' a vaginal birth. According to the hospital's birth register accounts, a prolonged labour was the main reason for emergency CS cases. However, what counted as 'prolonged' largely depended on the OGs' working hours 19:0018:00). Finally, the 'chance to have a normal birth' inevitably depended, to some extent at least, on each OG's performance points agreements (some earned more if they did a CS, some less) (Topçu, 2019: 156-157).

As a result, women only had a partial choice when it came to vaginal births. The situation for CS births was different. Women who had requested a CS from the start (i.e. not those who did not want a CS but who ended up having one during labour or because a complication had been identified ${ }^{8}$ ) had to pay the full cost of the operation. Indeed, an official new birth category (and billing structure) had been introduced within the private sector since the 'CS law' had come into force called 'C-sections on maternal demand'. This category covered cases in which the pregnant women made an explicit demand for a CS from the outset (i.e. not during labour or when a complication, such as a breech position, was identified). In such cases, the women were asked to sign a document confirming they were aware they would not benefit from public health insurance cover. The women's choice to have a CS was thus transformed either into a commodity that could be sold or into an individual need or expenditure from which the state had withdrawn. It should however

${ }^{8}$ According to a national survey, this was approximately $50 \%$ of all women who had a CS delivery. 
also be noted that, according to the interviews I conducted, when a pregnant woman could not fully afford the CS costs, it was possible to come to an 'arrangement' with the OG. The fact that vaginal birth anxiety was considered by law to be a medical reason for a CS facilitated such arrangements.

More research on the distribution of 'C-sections on maternal demand' vs. 'C-sections for medical reasons' in the private sector is necessary in order to fully understand whether Turkey has been facing a significant transfer of CS cost-bearing from the state to the individual (i.e. patients) or whether the change rather concerns a shift from state-funded CSs carried out in state hospitals to state-funded CSs carried out in private hospitals (with out-of-pocket fees for patients). I argue that in both cases, the private hospitals have emerged the winners from the 'caesarean law' because more and more women anxious about vaginal birth have come 'knocking on the doors of private hospitals', as one hospital manager put it. On the flip side of this, women, women's demands and women's needs for a safe, empowering birth experience seem to have been mostly pushed aside.

\section{Conclusion}

Be it caesarean or vaginal, hospital birth has become an authoritarian and traumatic experience for many women in the world (Diniz et al. 2018). Feminist mobilisations against obstetric violence have relevantly acquired an international audience since early 2010s. Among many issues denounciated in this frame, verbal violence of health professionnals, lack of assistance to women, denial of their sufferings (e.g. when local anesthesia does not work out well) and unjustified interventions, such as 'abusive' C-sections or episiotomy cuts or forceps use, can be mentioned at first place. Too much medical interventionism or too litle individualized care indeed can have longterm and even dramatic consequences for women. Traumatic birth experiences can engender post-partum anxiety, depression and even suicides (see also Göbelez in this volume). According to a survey conducted in 2011 among 1010 Turkish women, approximately one third of them suffer(ed) from post-partum depression, a rate much higher than the ones in countries like United Kingdom $(12,8 \%)$, France $(8,5 \%)$ or Sweden $(12,4 \%)$ (Unsal Altan et al. 2018).

The necessity to respect women's right to choose the way they want to live her birth experience is often put forward as a means to prevent such traumas. Albeit its undisputably fair nature, such a proposition is however more theoretical than feasible in many contexts becase birth in hospital is more often than not governed by pre-established norms and protocols than by a large set of possibilities of choice offered to women. To take one example, even choosing one's birth position is impossible in many hospital environments around the world. Furthermore, as this chapter has demonstrated, when exigencies of security combine with other ideologies 
such as conservatism and neoliberalism, « woman's choice » serve above all as a strategic and discursive tool of governmentality, despite the fact that neither women nor their preferences or wellbeing are placed at the center of political and medical concern.

It can be safely argued that the brutish character of the governmental critique of national CS epidemics (" caesarean delivery is a murder») in 2012 has contributed to such an exclusion of women from what they concern them at first place : the improvement of their birth conditions and the co-design of their (future) birth experience. Indeed, the too openly conservative nature of JDP's CS polemic prevented, at least to a certain extent, the rise of a social reflexivity on inconvenients of CSs and of technocratic birth on the overall. It rather provoked a polarised controversy in which a veritable critique of techno-medical colonisation of women's bodies and autonomy, via normalized CSs, was not involved. The CS abuse as a health problem was rendered occulte, whilst the debate was rather framed, by both the regulatory bodies and the medical actors, as the one «for or against the governmental harrassing on obsgyns", or "for or against a greater political control on women's lives/bodies ». In short, criticizing CS was perceived, by many, as «being against doctors», or rather as " being against women», «being antifeminist », « supporting Erdogan ». These were short-term developments.

In the middle term, the 'CS law' and the political-economic regulations that followed came out to play a paradoxical role, as far as the settings and the findings of this ethnographic study are concerned. It exerted pressure on public hospitals, for the sake of greater efficiency, while the private ones, which theoretically were the major target of the government's CS regulations, seemed to maintain their autonomy, and even to boost their profits thanks to the 'law'. The category of 'CS on maternal demand' was formalized within this frame.

In short, the CS controversy was not followed by major institutional reforms capable of introducing deep changes in practices and mentalities toward a 'rehumanisation' of childbirth and a 're-empowerment' of women. As a result, a significant number of women continue to prefer and even desire a caesarean birth, as they want to avoid episiotomy cuts or lack of care during painful labour. Those who prefer vaginal birth, on the contrary, either do not have it, especially if they choose a private hospital, or have it but in a painful way or without sufficient physical or psychological preparation prior to birth. In the middle of all these developments, to be sure, a critical evaluation of CS abuse as a health problem, but also as a feminist problem, as a cultural problem, and as a (bio)political problem, has to wait for new tomorrows. 


\section{References}

Acar F. \& Altinok G. 2013. The 'politics of intimate' at the intersection of neo-liberalism and neo-conservatism in contemporary Turkey. Women's Studies International Forum, $41: 14-$ 23.

Arman A. 2015. « Hastane ve doktor hatasına rekor tazminat: 2.5 milyon lira » (Record compensation for medical error: 2.5. million lira), Hürriyet, 04/01/2015 https://www.hurriyet.com.tr/yazarlar/ayse-arman/hastane-ve-doktor-hatasinarekor-tazminat-2-5-milyon-lira-27888991

Cindoğlu, D., \& Sayan-Cengiz, F. (2010). Türkiye'de Doğumların Medikalizasyonu: Feminist Bir Bakışla Sezaryen Problemini Düşünmek [Medicalisation of childbirth in Turkey: Reflecting on the caesarean problem from a feminist viewpoint]. In 2. Kadın Hekimlik ve Kadın Sağlığı Kongresi Kongre Kitabı (Congress Book of the 2nd Gynaecology-Obstetrics and Women's Health Congress) (pp. 51-64). Ankara: University of Ankara.

Davis-Floyd, R. E., \& Sargent, C. F. (Eds.). (1997). Childbirth and authoritative knowledge. Crosscultural perspectives. California: University of California Press.

Diniz, S. G., \& Chacham, A. S. (2004). 'The cut above' and 'the cut below'. The abuse of caesareans and episitomy in Sao Paolo, Brazil. Reproductive Health Matters, 12(23), 100110.

Diniz Carmen Simone Grilo, Daphne Rattner, Ana Flávia Pires Lucas

d'Oliveira, Janaína Marques de Aguiar \& Denise Yoshie Niy. 2018. « Disrespect and abuse in childbirth in Brazil: social activism, public policies and providers' training ", Reproductive Health Matters, 26:53, 19-35.

Eren Vural I. 2017. «Financialisation in health care : an analysis of private equity fund investments in Turkey », Social Science and Medicine, 187 : 276-286.

Gaskin, I. M. (2008). Ina may's guide to childbirth. London: Vermilion.

Gok M.S., Altindag E. 2015. « Analysis of the cost and efficiency relationships : experience in the Turkish pay for performance system », European Journal of Health Economy, 16 : 459469.

Göbelez S. «Tactics of Women up against Obstetrical Violence and the Medicalization of Childbirth in Turkey », in this volume.

Hamzaoglu N., Türk B. 2019. «Prevalence of physical and verbal violence against health care workers in Turkey », International Journal of Health Services, 49(4), p. 844-861.

Jordan, B. 1978. Birth in Four Cultures: A Crosscultural Investigation of Childbirth in Yucatan, Holland, Sweden, and the United States. California: Eden Press Women's Publications. 
Juven P., Une santé qui compte? Les coûts et les tarifs controversés de l'hôpital public. Paris : PUF.

Kitzinger S. A Passion for Birth: My Life: Anthropology, Family and Feminism, Pinter \& Martin 2015.

Maffi, I. 2015. «The Detour of an Obstetric Technology: Active Management of Labor Across Cultures », Medical Anthropology, 35, 1, p. 17-30.

Mc Callum, C. (2005). Explaining caesarean section in Salvador da Bahia, Brazil. Sociology of Health \& Illness, 27(2), 215-242.

Ministry of Health of Turkey, 2010. Management Guide for Vaginal and Caesarean Deliveries (Dogum ve Sezaryan Eylemi Yönetim Rehberi), Ankara: Republic of Turkey Ministry of Health.

Ministry of Health of Turkey 2017, Women's Diseases and Birth Commission Report (Kadin Hastaliklari ve Dogum Komisyonu Raporu), Istanbul : Istanbul Directory of Health/ Ministry of Health.

Ministry of Health of Turkey 2018. Health statistics year book 2017. Ankara : Republic of Turkey Ministry of Health.

Morris, T. (2013). Cut it out. The C-section epidemic in America. New York: NYU Press.

Odent, M. (1992). The nature of birth and breastfeeding. New York: Praeger.

O'Neil M. L. 2017. "Abortion services at hospitals in Istanbul », The European Journal of Contraception and Reproductive Health Care, 22(2), p. 88-93.

Omay E.G.G., Cengiz E., 2013, «Health Tourism in Turkey: Opportunities and Threats », Mediterranean Journal of Social Sciences, 4, 10, p. 424-431.

Özer Ö., Gün Ç., Saygili M. ( 2016). « Cost of caesarean section rates in Turkey and their burden in the Turkish health economics », Proceedings of the 24th International Academic Conference, 28/06-01/07/2016.

Roberts, E. F. S. (2012). Scars of the nation: Surgical penetration and the Ecuadorian state. The Journal of Latin American and Caribbean Anthropology, 17(2), 215-237. Rosa, H. (2015). Social acceleration: A new theory of modernity. Columbia: Columbia University Press.

Sarda, G. (2011). Artificially maintained scientific controversies, the construction of maternal choice and caesarean section rates. Social Theory \& Health, 9(2), 166-182.

Topçu S. (2019) Caesarean or vaginarean epidemics ? Techno-birth, risk and obstetric practice in Turkey, Health, Risk \& Society, 21:3-4, 141-163 
Topçu S., Brown P. 2019. The impact of technology on pregnancy and childbirth: creating and managing obstetrical risk in different cultural and socio-economic contexts, Health, Risk \& Society, 21:3-4, 89-99.

Turkish Medical Association, 2011, « Tam Gün' mü? Ulus ötesi işbirliğine ucuz işgücü mü? » (Full time? Or cheap workforce for a supranational collaboration?), Press release, 29.08.2011.

Turkish Medical Association (2013), Özel hastanede avuç izi parmak izi verirken bir kez daha düsünün! (Think twice before you give a finger and palm print in private hospitals !), Press Release, 03.12.2013.

Turkish Medical Association, 2018a, Saglikta donusum Programi Çöktü. Ne Dediler Ne oldu? (The Health Transformation Programme Collapsed. What did they promise and what happened ?), Supplement to Tip Dunyasi Gazetesi (Gazette of the Medical World), March 2018.

Turkish Medical Association, 2018b Özel Saglik Sektorunde Çalisma ve Ucretlendirme Biçimleri (Forms of Work and Remuneration in the Private Health Sector), Istanbul : TTB Yayinlari.

Union of Chambers and Commodity Exchanges of Turkey (Türkiye Odalar ve Borsalar Birligi). 2017. Turkey Healthcare Landscape. Report. https://www.tobb.org.tr/saglik/20171229-tss-genel-bakis-en.pdf

Unsal Altan S., Ozturk R., Güleç Satir D., Ildan Calim S., Karaoz Weller B, Amanak K., Saruhan A., Sirin A., Akerca F., 2018, « Relation between mothers' types of labor, birth interventions, birth experiences and postpartum depression : a multi-centre followup study », Sexual and Reproductive Healthcare, 18, p. 13-18.

Visser, G.H. A., Diogo Ayres-de-Campos, Eytan R Barnea, Luc de Bernis, Gian Carlo Di Renzo, Maria Fernanda Escobar Vidarte, Isabel Lloyd, Anwar H Nassar, Wanda Nicholson, P K Shah, William Stones, Luming Sun, Gerhard B Theron, Salimah Walani, 2018, « FIGO position paper: how to stop the caesarean section epidemic», The Lancet, $\mathrm{n}^{\circ} 392$ (13/10/2018).

Wendt, C., Agartan T. I., Kaminska M. E., 2013, « Social health insurance without corporate actors: changes in self-regulation in Germany, Poland and Turkey», Social Science \& Medicine, 86, p. 88-95.

World Health Organization (2015). WHO Statement on Caesarean Section Rates https://apps.who.int/iris/bitstream/handle/10665/161442/WHO RHR 15.02 eng.pdf?se quence $=1$

Wolf, J. (2018). Cesarean Section. An American history of risk, technology and consequence. Baltimore: John Hopkins University Press.

World Bank 2018, Turkish Health Transformation Program and Beyond, Results Briefs, 2 April 2018.< $\quad$ https://www.worldbank.org/en/results/2018/04/02/turkish-healthtransformation-program-and-beyond> 
